Tropical Journal of Pharmaceutical Research March 2019; 18 (3): 449-458

ISSN: 1596-5996 (print); 1596-9827 (electronic)

(C) Pharmacotherapy Group, Faculty of Pharmacy, University of Benin, Benin City, 300001 Nigeria.

\title{
Quantification of carbon dioxide released from effervescent granules as a predictor of formulation quality using modified Chittick apparatus
}

\author{
Muhammad Sohail Arshad ${ }^{1}$, Kabindra Sedhain ${ }^{1}$, Amjad Hussain ${ }^{2 \star}$, Nasir \\ Abbas $^{2}$, Jahanzeb Mudassir ${ }^{1}$, Faisal Mehmood ${ }^{2}$, Muhammad Irfan ${ }^{3}$, Sumera \\ Latif $^{3}$ \\ ${ }^{1}$ Department of Pharmaceutics, Faculty of Pharmacy, Bahauddin Zakariya University, Multan, ${ }^{2}$ University College of Pharmacy, \\ University of the Punjab, Lahore, ${ }^{3}$ Department of Pharmaceutics, Faculty of Pharmaceutical Science, Government College \\ University Faisalabad, Pakistan
}

*For correspondence: Email: amjad_husein@hotmail.com; Tel: +92-42-99211616

Sent for review: 25 October 2018

Revised accepted: 20 February 2019

\begin{abstract}
Purpose: To develop a method for the measurement of carbon dioxide $\left(\mathrm{CO}_{2}\right)$ released from effervescent formulations.

Methods: Effervescent granules were prepared using sodium bicarbonate and citric acid by fusion and solvent-assisted granulation methods. The amount of $\mathrm{CO}_{2}$ released was determined from the maximum pressure of gas release, time profile of pressure gradient using modified Chittick apparatus and gravimetric changes following effervescence.

Results: The amount of $\mathrm{CO}_{2}$ released from effervescent granules prepared by fusion method was $8.125,8.763$ and $7.98 \mathrm{mM} / \mathrm{g}$ measured by ideal gas equation, pressure gradient and gravimetric method, respectively. The formulation prepared by solvent-assisted granulation showed 5.525, 5.475 $5.36 \mathrm{mM} / \mathrm{g}$ of carbon dioxide measured by the above three methods, respectively. The effervescent granules prepared by fusion method showed approximately $2 \%$ loss in effervescence. However, approximately $39 \%$ loss in effervescence was observed for the formulation prepared by solventassisted granulation. The commercial products showed a loss in effervescence in the range of $5-15 \%$. Conclusion: Modified Chittick's apparatus is a useful analytical tool for monitoring of the $\mathrm{CO}_{2}$ from effervescent granules as a function of method of preparation.
\end{abstract}

Keywords: Modified Chittick device, Effervescence, Fusion, Carbon dioxide ( $\left.\mathrm{CO}_{2}\right)$, Gravimetric method, Effervescent granules

\begin{abstract}
This is an Open Access article that uses a funding model which does not charge readers or their institutions for access and distributed under the terms of the Creative Commons Attribution License (http://creativecommons.org/licenses/by/4.0) and the Budapest Open Access Initiative (http://www.budapestopenaccessinitiative.org/read), which permit unrestricted use, distribution, and reproduction in any medium, provided the original work is properly credited.
\end{abstract}

Tropical Journal of Pharmaceutical Research is indexed by Science Citation Index (SciSearch), Scopus, International Pharmaceutical Abstract, Chemical Abstracts, Embase, Index Copernicus, EBSCO, African Index Medicus, JournalSeek, Journal Citation Reports/Science Edition, Directory of Open Access Journals (DOAJ), African Journal Online, Bioline International, Open-J-Gate and Pharmacy Abstracts

\section{INTRODUCTION}

Effervescence is defined as the evolution of gas bubbles from a liquid mixture as a result of a chemical reaction [1]. This phenomenon is widely investigated by scientists working in different domains of science including dietary supplements [2,3], cosmetics [4] horticulture [5], agriculture [6], archeology, and pharmaceuticals (effervescent granules) etc. British 
Pharmacopoeia (BP) defines effervescent tablets as "Uncoated tablets generally containing acid substances and carbonates or hydrogen carbonates, which react rapidly in the presence of water to release carbon dioxide" [7]. Effervescent formulations are meant to mask undesirable taste of medicinal agent(s) [8]. Moreover, in combination with certain polymers provide buoyance to the drug delivery system resulting in gas generating floating tablets frequently designed to achieve localized drug release in the stomach or sustained release of drug to the intestine [9].

Different methods are used to measure effervescence including gravimetric, volumetric and gasometric $[10,11,12]$.

Although the gasometric method is reported as the most efficient among the studied methods, its adaptation in pharmaceutical industry is limited; one of the reasons is that the conventional apparatus is primitive in nature and it cannot be used to determine the time profile of effervescence in a pharmaceutical formulation [10]. The measurement of effervescence time profile is desirable as it determines the time period over which a formulation effervesces at acceptable intensity. Since the formulation development and process optimization requires an understanding of factors affecting the efficiency of a product. The performance of effervescent preparations is often influenced by process control, material control and evaluation of storage condition.

Processing conditions such as degree of mixing as well as the release/contact with the binder solvent need to be studied at different stages of the preparation in order to explore in-process reactivity of the ingredients. The situation might be more challenging at bulk manufacturing where the suboptimal mixing of the ingredients would affect the effervescence of resultant mixture [1]. The aim of the study was to develop a reliable method to record time profile of effervescence using modified Chittick apparatus. The effervescence profiles were validated using three approaches namely; ideal gas equation, effervescence time profile and gravimetric method. Two formulations prepared using solvent assisted granulation and fusion based granulation as well as two commercially available effervescent granules (Brand I and II) were characterized for degree of effervescence using presently developed method (Modified Chittick apparatus). The results from these formulations were compared with the established methods for the measurement of effervescence.

\section{EXPERIMENTAL}

Calcium carbonate, sodium bicarbonate, citric acid and hydrochloric acid, used in this study were purchased from Sigma Aldrich, Germany. Ethanol was purchased from Merck Germany. Distilled water was obtained from in house facility.

\section{Equipment}

The principle of gasometric system used in this study was adapted from the Chittick apparatus as reported by Huang et al $[5,11]$. The equipment (Figure 1) comprises of a decomposition flask $250 \mathrm{~mL}$ connected to an acid dispensing burette and a gasometric tube coupled with pressure monitoring U-shaped system via a connecting tube and stop cork.

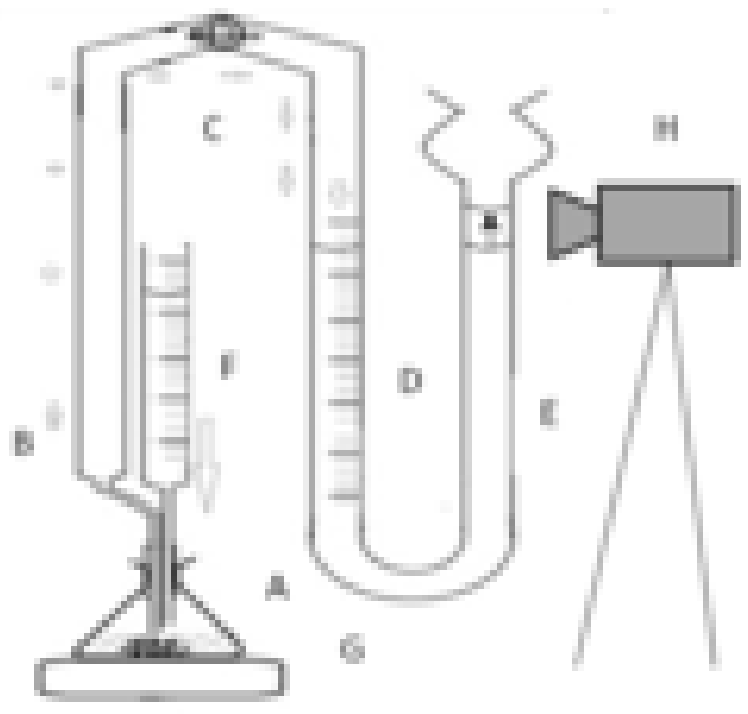

Figure 1: Gasometric system for $\mathrm{CO}_{2}$ measurement adapted from Chittick apparatus. The decomposition flask (A), connected to a graduated gas-measuring burette (D) via gas tube (B) and stopcock (C), water level burette $\mathrm{E}$. A connects to acid-dispensing burette $(F)$, magnetic stirrer $(G)$, video recording Camera $(H)$ records the water level in the burette $(E)$

\section{Principle of operation}

Acid/water was dispensed from acid dispensing burette $(F)$ to the decomposition flask $(A)$ at volumes $(5-17 \mathrm{~mL})$ sufficient to react with substrate (i.e. prepared effervescent granules or commercial formulations). The gas evolved as a result of acid-base reaction pushes the water in pressure monitoring column (D). The volume of $\mathrm{CO}_{2}$ was recorded from changes in water level in the water-level- burette (D) using static video camera (H) (8MPix, F2.0, LED, autofocus, Samsung, Japan). 
The stoichiometry of effervescent reaction is expressed as in Eqs 1 and 2 [4].

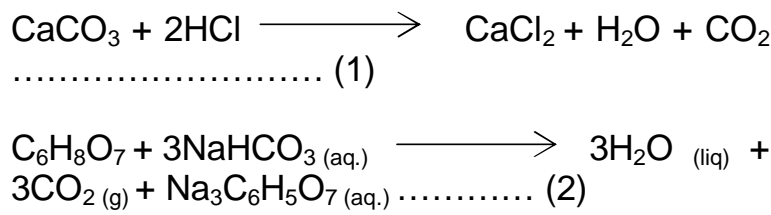

The number of moles of $\mathrm{CO}_{2}$ can be calculated from the displaced $\mathrm{CO}_{2}$ volume using the ideal gas equation (Eq 3$)$ [5].

$\mathrm{N}_{\mathrm{CO} 2}=\mathrm{P}_{\mathrm{CO} 2} \mathrm{~V}_{\mathrm{CO} 2} / \mathrm{RT}$

where $\mathrm{N}$ is the no. of mole of $\mathrm{CO}_{2}$ liberated from the reaction, $\mathrm{P}_{\mathrm{CO} 2}$ represents partial pressure of $\mathrm{CO}_{2}(\mathrm{~Pa}), \mathrm{V}_{\mathrm{CO} 2}(\mathrm{~L})$ is the volume measured from device which can be obtained from subtracting the volume of $\mathrm{HCl}$ used from the total volume of displaced liquid as it is closed system (Eq 4).

$\mathrm{V}_{\mathrm{CO} 2}=$ volume of total displaced water $\left(\mathrm{V}_{1}\right)$ volume of $\mathrm{HCl}$ consumed $\left(\mathrm{V}_{2}\right)$

where $R$ is the universal gas constant with value of $0.008314 \mathrm{~L}$. Pa. $\mathrm{K}^{-1} \mathrm{~mol}^{-1}$ and T is temperature $(\mathrm{K})$. Furthermore, the time profile of changes in water levels in the column was used as a function of amount of gas generated in the reaction mixture.

\section{Calibration of method}

The output from modified Chittick apparatus was calibrated using the following methods.

Method I: Ideal gas equation method

Accurately weighed $0.05-10 \mathrm{mM}(0.05-1 \mathrm{~g})$ calcium carbonate was reacted with sufficient volume of $6 \mathrm{M} \mathrm{HCl}$ and volume of $\mathrm{CO}_{2}$ released was determined by subtracting the volume contributed by acid from total volume displacement recorded at gas measuring burette. The temperature and barometric pressure of air surrounding the instrument was also recorded.

Method II: Effervescence - time profile

As an alternate approach, the pressure exerted by $\mathrm{CO}_{2}$ gas on the column of measuring burette $(\mathrm{Pa})$, was plotted as a function of time (Sec), at which successive pressure was noted (Figure 3). The gas pressure inside the column was calculated by using the following expression:

$\mathrm{P}=$ h.d.g
Where $P$ is Pressure inside column of measuring burette $(\mathrm{Pa}), \mathrm{h}$ denotes the height of displaced water in column (in meter), $\mathrm{d}$ is density of water at $25{ }^{\circ} \mathrm{C}\left(\mathrm{kg} / \mathrm{m}^{3)}\right.$ and $\mathrm{g}$ is acceleration due to gravity $\left(\mathrm{m} / \mathrm{s}^{2}\right)$.

\section{Method III: Gravimetric method}

In a $250 \mathrm{~mL}$ beaker, $\sim 4$ oz. (118.3 $\mathrm{mL}) \mathrm{HCl}$ was placed on analytical balance and tarred. Accurately weighed calcium carbonate samples $(1,2,3$, and $5 \mathrm{~g}$, respectively) were added to acid and weight changes following effervescence were recorded.

\section{Preparation of granules}

Effervescent granules containing citric acid and sodium bicarbonate at weight ratio 1:3 [13] were prepared by two methods; Solvent method and Fusion method [13]. The fusion method involved heating the homogenous mixture of reactants i.e. salt and acids in a porcelain dish over the water bath at $90{ }^{\circ} \mathrm{C}$ resulting in the release of water of crystallization from citric acid which act as binder to transform the powdered mixture into a dough. Granules formed by passing the wet mass through a screen of mesh number 16 (pore size $1.19 \mathrm{~mm}$ ) were dried at $50{ }^{\circ} \mathrm{C}$ for $4 \mathrm{~h}$ and preserved in an airtight container at room temperature $\left(25{ }^{\circ} \mathrm{C}\right)$ for further analysis. For solvent assisted granulation, powdered components (citric acid and sodium bicarbonate, equi-mass $10.0 \mathrm{~g}$ ) were mixed with $5 \mathrm{~mL}$ of methanol $(75 \% \mathrm{v} / \mathrm{v})$ to form dough which was subsequently passed through a screen of mesh number 16 to produce granules. These granules were then dried at $50^{\circ} \mathrm{C}$ for $4 \mathrm{~h}$ in hot air oven to ensure the complete evaporation of methanol and resultant sample was preserved in an airtight container at room temperature $\left(25{ }^{\circ} \mathrm{C}\right)$ until further used.

The commercial brands were evaluated for the amount of $\mathrm{CO}_{2}$ release and deviation from the ideal yield. Different brands of effervescent preparations containing calcium carbonate as effervescent salt were selected for estimation of $\mathrm{CO}_{2}$ release behavior. Mass of each sachet coded as Brands I and II, respectively, was introduced to the reaction vessel and the amount of calcium carbonate was determined.

\section{Characterization of granules}

Prepared granules were characterized for bulk properties such as bulk density, compressibility index, flow properties, particle size distribution and loss on drying in order to determine mass flow from the container [14-17]. 


\section{Degree of effervescence}

The prepared granules (two formulations) as well as the commercial formulations (brands I and II) were characterized for amount of $\mathrm{CO}_{2}$ released using modified Chittick apparatus. Degree of effervescence was assessed by using maximum gas release as well as effervescence-time profile data. Validity of the measurement approaches was also explored by comparing the output from above stated two methods.

\section{RESULTS}

\section{Calibration of modified Chittick apparatus}

The effervescence response recorded by modified Chittick apparatus has been validated using three approaches namely ideal gas equation, effervescence time profile and gravimetric method. The results are described as follows:

\section{Calibration method I (Ideal gas equation)}

Amount of carbon dioxide release plotted against the weight of calcium carbonate followed a linear regression relationship with a correlation coefficient $\left(R^{2}\right)$ value 0.999 (Figure 2).

The moles of $\mathrm{CO}_{2}$ released were used to calculate mole of calcium carbonate consumed in the acid based reaction (Eq 6).

$\mathrm{CaCO}_{3}(\mathrm{n})=\mathrm{PV} / \mathrm{RT}$

where $\mathrm{P}$ represents partial pressure of $\mathrm{CO}_{2}(\mathrm{~Pa})$, $\mathrm{V}(\mathrm{L})$ is the volume measured from device which can be obtained from subtracting the volume of $\mathrm{HCl}$ used from the total volume of displaced liquid as it is a closed system, $\mathrm{R}$ is universal ideal gas constant and $\mathrm{T}$ is temperature of surrounding environment.

The amount of $\mathrm{CO}_{2}$ recorded by modified Chittick apparatus was in close agreement with the one calculated from chemical reaction of stoichiometric concentrations of sodium bicarbonate and citric acid. This correlation suggest that ideal gas equation can be used explain the pressure changes recorded from modified Chittick apparatus (table 1).
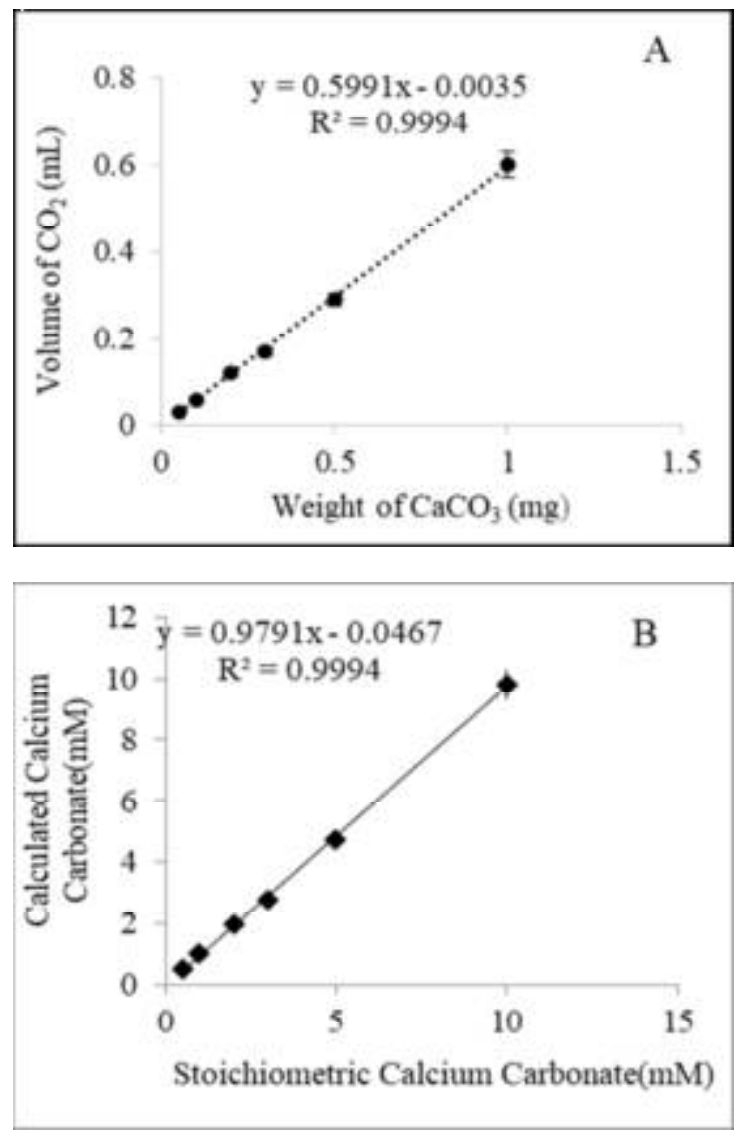

Figure 2: Calibration curve of gasometric system using calcium carbonate $(A, B)$

\section{Method II (Effervescence time profile)}

Barometric changes recorded from effervescence reaction were plotted as a function of time and the results are described in Figure 3.

Table 1: Carbon dioxide (mole) release from calcium carbonate using Ideal gas law

\begin{tabular}{ccccccc}
\hline $\begin{array}{c}\text { Initial wt } \\
(\mathbf{g})\end{array}$ & $\begin{array}{c}\text { Initial } \mathbf{m M} \\
\mathbf{C a C O 3}(\mathbf{g})\end{array}$ & $\begin{array}{c}\text { Dif.in water } \\
\text { level }(\mathbf{m l}) \\
\mathbf{V}_{\mathbf{1}}\end{array}$ & $\begin{array}{c}\text { Vol. of HCl } \\
\text { used }(\mathbf{m l}) \\
\mathbf{V}_{\mathbf{2}}\end{array}$ & $\begin{array}{c}\text { Vol.of carbon } \\
\text { dioxide }(\mathbf{L}) \\
\mathbf{V}=\left(\mathbf{V}_{\mathbf{1}}-\mathbf{V}_{\mathbf{2}}\right)\end{array}$ & $\begin{array}{c}\text { Calculated mM } \\
\mathbf{P V}(\mathbf{P a} . \mathbf{L})\end{array}$ & $\begin{array}{c}\mathbf{C a C O}_{3}(\mathbf{n})= \\
\mathbf{P V} / \mathbf{R T}\end{array}$ \\
\hline 0.05 & 0.5 & 6.0 & 5.97 & 0.00003 & 0.001215 & 0.0490 \\
0.1 & 1 & 6.8 & 6.74 & 0.000059 & 0.002431 & 0.981 \\
0.2 & 2 & 13.0 & 12.88 & 0.000119 & 0.004862 & 1.96 \\
0.3 & 3 & 16.0 & 15.83 & 0.00017 & 0.006888 & 2.78 \\
0.5 & 5 & 18.0 & 17.71 & 0.000289 & 0.011750 & 4.74 \\
1.0 & 10 & 20.0 & 19.4 & 0.0006 & 0.024312 & 9.81 \\
\hline
\end{tabular}

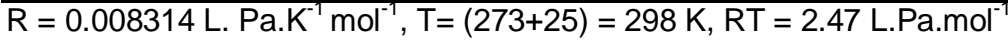




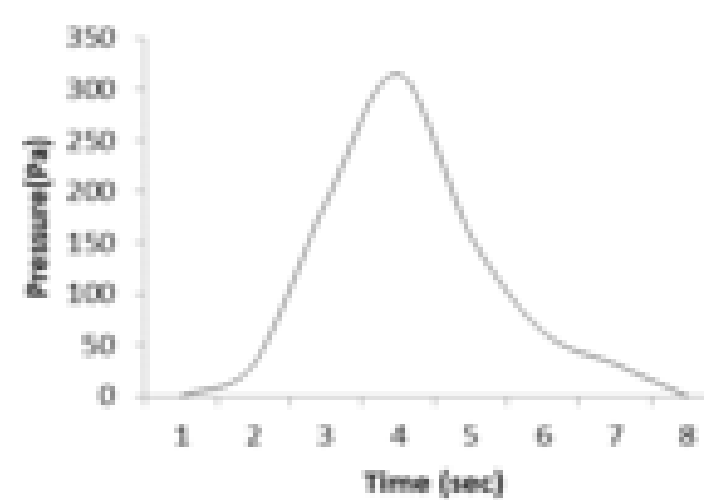

Figure 3: A representative plot of effervescence-time profile using calcium carbonate

The area under the curve (AUC, Pa.S) of pressure-time graph was calculated by trapezoidal formula as in Eq 7.

$A U C=1 / 2\left(P_{1}+P_{2}\right) \times\left(t_{2}-t_{1}\right)$

The AUC plotted as a function of sample weight (Figure $4 \mathrm{~A}$ ) demonstrates a good correlation $\left(\mathrm{R}^{2}\right.$ $=0.995)$ with a linear regression equation $(y=$ $14932 x+2113.2)$.

AUC was also plotted as a function of volume of gas liberated during the effervescent reaction (Figure 4B). A good correlation $\left(R^{2}=0.994\right)$ with linear equation suggest a reliable application of AUC as a predictor of either volume of $\mathrm{CO}_{2}$ or amount of salt consumed in the reaction.

\section{Method III (Gravimetric method)}

In this method, the weight loss was presumed to be due to evaporation of $\mathrm{CO}_{2}$ from the system. Weight changes over the time were recorded to demonstrate the progress of acid base reaction (Figure 5A). Subsequently, the mass of $\mathrm{CO}_{2}$ (expressed as millimoles; $\mathrm{mM}$ ) evolved from different amount of $\mathrm{CaCO}_{3}$ were plotted (Figure $5 B)$. The amount of $\mathrm{CO}_{2}$ recovered from acid

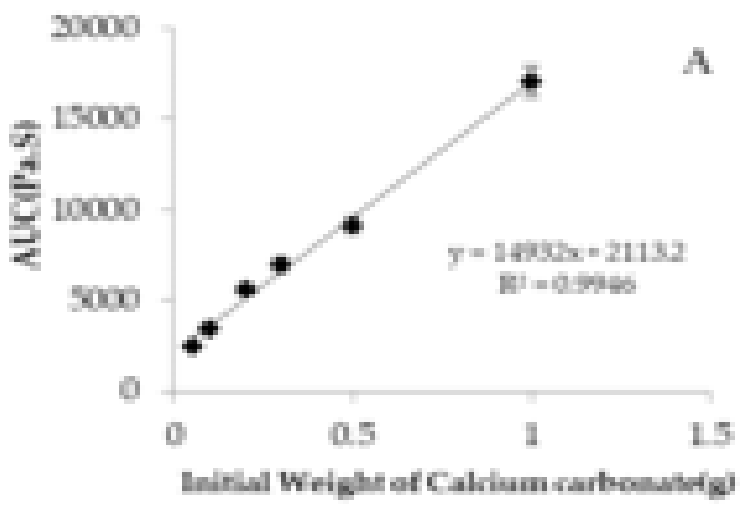

bases reaction was plotted as a function of stoichiometrically predicted carbon dioxide (millimoles; mM) (Figure 5C). The amount of carbon dioxide released followed a linear regression relationship with predicted value (correlation coefficient $R^{2}$ value of 0.999 ). This confirms the suitability of gravimetric method for the estimation of $\mathrm{CO}_{2}$ from effervescent preparations.

\section{Bulk properties of granules}

The formulation prepared in this study as well the commercial brands were assessed for bulk properties to determine their suitability for use. The results of bulk characterization parameters listed in Table 2 suggest that all of the samples had angles of repose between $20^{\circ}-40^{\circ}$ indicating reasonable flow potential $[14,18,19]$. Likewise, the compressibility Index value $<15$ also confirmed good flow behavior. All of the samples, except those prepared using solvent assisted granulation demonstrate loss on drying $<4 \%$. The latter described $12 \%$ weight loss indicating the presence of solvents in these granules.

\section{Degree of effervescence from granules}

\section{Method I: Ideal gas equation method}

Effervescent granules weighing $0.8 \mathrm{~g}$ were calculated to release $7.143 \mathrm{mM}$ of $\mathrm{CO}_{2}$ following complete reaction with acid at stoichiometric ratios. This theoretical yield of carbon dioxide is seldom achieved; some of the reasons for this suboptimal output $\left(\mathrm{CO}_{2}\right)$ include depletion of carbonate during manufacturing and impurities in the reactants. Nevertheless, degree of effervescence as a function of method of preparation remains a question for the formulation scientists.

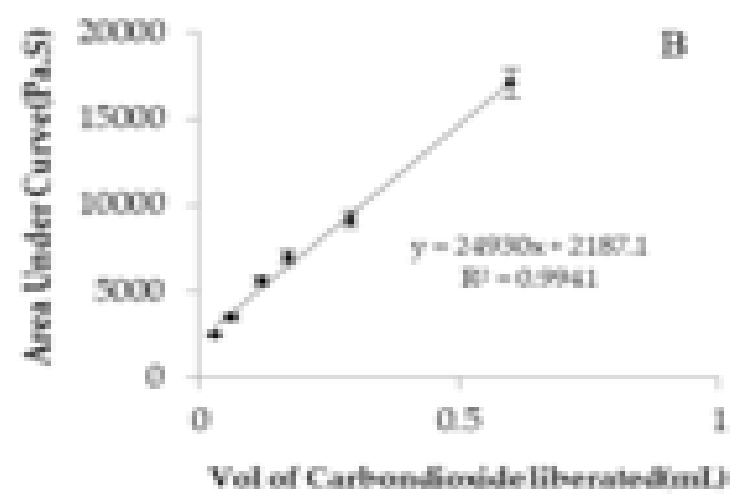

Figure 4: Calibration curve of effervescence -time profile, AUC of standard sample Vs weight (Figure: A). Graph relating volume of carbon dioxide $(\mathrm{mL})$ liberated vs AUC in effervescence time profile (Figure: $\mathrm{B}$ ) 

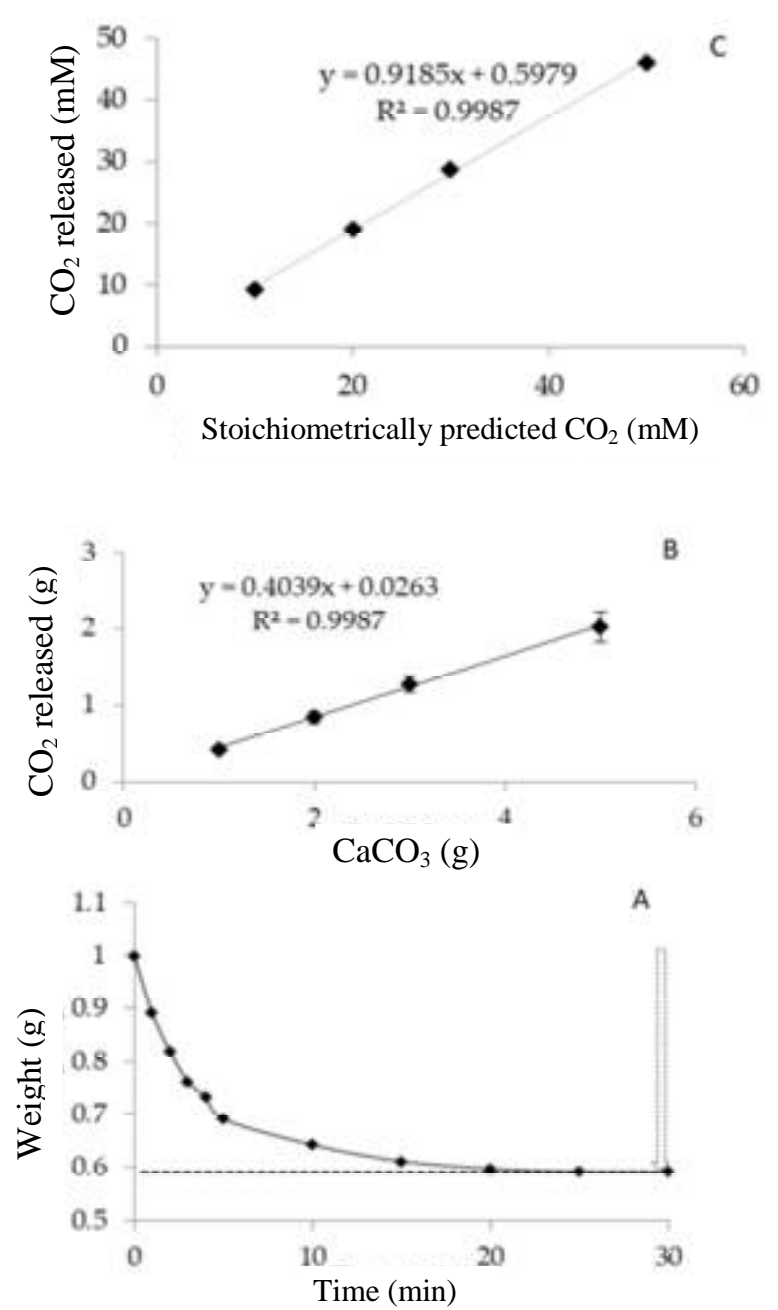

Figure 5: Calibration curve of $\mathrm{CaCO}_{3}$ from gravimetric data: Graph A represents weight of sample vs. time, Graph B denotes weight of $\mathrm{CO}_{2}$ released vs. weight of $\mathrm{CaCO}_{3}$, Graph $\mathrm{C}$ shows weight of $\mathrm{CO}_{2}$ released vs. stoichiometrically predicted $\mathrm{CO}_{2}$

Amount of $\mathrm{CO}_{2}$ released from granules formulated by fusion method

Effervescent granules $(0.8 \mathrm{~g})$ formulated by fusion method released $6.568 \mathrm{mM}$ of $\mathrm{CO}_{2}$. Herein the amount of carbon dioxide released was $8.05 \%$ less than that expected from stoichiometric reaction. Provided that the purity of the sample was $100 \%$. This decrease is due to partial decarboxylation of the reactants following heat assisted release of water of crystallization from monobasic acid which act as a reaction medium for acid and carbonates.

\section{Amount of $\mathrm{CO}_{2}$ released from granules formulated by solvent method}

The amount of carbon dioxide released from the effervescent granules $(0.8 \mathrm{~g})$ prepared by solvent assisted granulation method was $4.420 \mathrm{mM}$. The amount of $\mathrm{CO}_{2}$ released in this formulation was $38.11 \%$ lower than the stoichiometrically expected yield. The results also depict a significantly lower effervescence $(32.70 \%)$ than that of the counterparts prepared by the fusion method (6.568 mM) (Table 3).

The inclusion of solvent (specially, water portion of hydro-alcoholic solvent) during the granulation procedure promotes a chemical reaction between bicarbonates and acid resulting in an unintended decarboxylation. Although the inclusion of solvent benefits with an easier preparation of effervescent granules, it also results in a significant loss in the critical quality attribute (effervescence) of the product.

\section{Method II: Effervescence-time profile}

The time profile of effervescence from granular powder showed a single peak (Figure 6) referring to the reaction between the monobasic acid and base. In its simplest description the effervescence profile can be described in terms of maximum time point, total duration of effect and area under the curve.

Maximum gas pressure observed as peak in the time profile was $1134 \mathrm{~Pa}$ for granules prepared by fusion method. The same event was recorded as $1008 \mathrm{~Pa}$ for granules prepared by solvent assisted granulation technique (Figure 6).

Table 2: Characteristics of sample granules and marketed brands

\begin{tabular}{|c|c|c|c|c|}
\hline \multirow[b]{2}{*}{ Parameter } & \multicolumn{2}{|c|}{$\begin{array}{c}\text { Sample } \\
\text { (Citric acid: Sodium Bicarbonate=1:3) }\end{array}$} & \multicolumn{2}{|c|}{ Commercial brand } \\
\hline & Sample 1 & Sample 2 & & Brand II \\
\hline Angle of repose ( ${ }^{\mathrm{U}}$ ) & 25 & 24.4 & 25.12 & 29.33 \\
\hline $\begin{array}{l}\text { Compressibility Index } \\
(\%)\end{array}$ & 14.60 & 10.48 & 18.75 & 11.76 \\
\hline $\begin{array}{l}\text { Bulk Density }\left(\mathrm{g} / \mathrm{cm}^{3}\right) \\
\text { LOD }(\%)\end{array}$ & $\begin{array}{l}0.04 \\
3.09\end{array}$ & $\begin{array}{c}0.04 \\
12.35\end{array}$ & $\begin{array}{l}0.67 \\
2.75\end{array}$ & $\begin{array}{c}0.625 \\
3\end{array}$ \\
\hline $\begin{array}{l}\text { Particle size distribution } \\
\text { (mean diameter in } \mathrm{mm} \text { ) }\end{array}$ & 1.101 & 1.101 & 0.102 & 0.100 \\
\hline
\end{tabular}


Effervescence time profile for samples prepared by fusion method was $21 \pm 1 \mathrm{sec}$ whereas the one prepared by solvent assisted granulation produce $\mathrm{CO}_{2}$ for $19 \pm 1 \mathrm{sec}$.

Results on area under the curve (AUC), calculated from trapezoidal method also revealed an area under the curve of $12,587 \mathrm{~Pa}$.S from effervescent granule prepared by fusion method. This is approximately 1.5 fold higher than the granules prepared by solvent assisted granulation approach $(8,662.5$ Pa.S $)$. These observations are in agreement with the estimates for amount of gas released in mole i.e. $7.015 \mathrm{mM}$ $(98.20 \%$ of expected gas yield) and $4.386 \mathrm{mM}$ (61.40\% of expected gas yield) for fusion and solvent assisted granules, respectively.

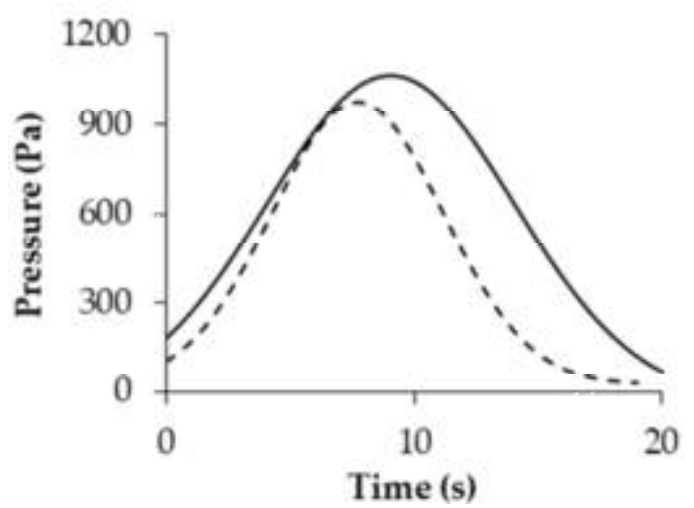

Figure 6: Effervescence-time profile of granules. Solid curve $\left(\_\right)$describes pressure gradients from granules prepared by fusion method; dotted curve (....) measures the time profile of granule prepared by solvent-assisted granulation method

It appears from the results that granule prepared by fusion method released higher concentration of $\mathrm{CO}_{2}$ as compared to the particulate counterparts prepared by solvent assisted granulation. A simple justification of this result includes a limited reaction of the materials during formulation. These findings are valuable in the screening of different methods used for the preparation of effervescent granules in terms of $\mathrm{CO}_{2}$ release.

Table 3: Percent difference between experimentally calculated mole of $\mathrm{CO}_{2}$

\begin{tabular}{lccc}
\hline & $\begin{array}{c}\text { METHOD I } \\
(\%)\end{array}$ & $\begin{array}{c}\text { METHOD II } \\
(\%)\end{array}$ & $\begin{array}{c}\text { METHOD } \\
\text { III (\%) }\end{array}$ \\
\hline $\begin{array}{l}\text { Sample I } \\
\text { \& Sample }\end{array}$ & 32.7 & 37.42 & 33.05 \\
II & & & \\
$\begin{array}{l}\text { Brand 1 \& } \\
\text { Brand II }\end{array}$ & 10.61 & 14.68 & 9.10 \\
\hline
\end{tabular}

Method III: Gravimetric method
By taking $3 \mathrm{~g}$ of granules, the amount of $\mathrm{CO}_{2}$ predicted stoichiometrically was $27.6704 \mathrm{mM}$. The observed $\mathrm{CO}_{2}$ released from the granule prepared by fusion and solvent assisted granulation methods was 23.9493 and 16.0874 $\mathrm{mM}$, respectively which accounts for 13.40 and $43.13 \%$ lower than the ideal effervescence yield, respectively.

The results from gravimetric analysis of effervescent granules suggest a difference of $33.05 \%$ in the effervescence when one switches from fusion to solvent assisted granulation. It is interesting to state that the results from all of the methods used for the measurement of effervescent were comparable and $33-37 \%$ less $\mathrm{CO}_{2}$ release was recorded in samples prepared by solvent assisted granulation approach.

\section{Amount of $\mathrm{CO}_{2}$ release from Commercial brands}

Method I: Ideal Gas equation method

The amount of $\mathrm{CO}_{2}$ calculated stoichiometrically $3.27 \mathrm{mM}$ for both Brands. However, the mass of $\mathrm{CO}_{2}$ release observed from brand I and II was $2.783,3.110 \mathrm{mM}$ respectively. The results suggest that brands I and II showed 14.92 and $4.89 \%$, respectively lower $\mathrm{CO}_{2}$ release than that of the expected yield.

\section{Method II: Time profile methodology}

The duration of effervescence peak for brand I was of $11 \mathrm{sec}$ while for brand II it was $14 \mathrm{sec}$ (Figure 7). The time profiles of brand I and II were characterized by $\mathrm{P}_{\max } 1017 \mathrm{~Pa}, 1008 \mathrm{~Pa}$ respectively with AUC 6516 and 7339 Pa.S, respectively.

The amount of $\mathrm{CO}_{2}$ released for brand I and II was 2.7300 and $3.200 \mathrm{mM}$ respectively from effervescence time profile while the amounts measured by method I was 2.780 and $3.110 \mathrm{mM}$ respectively. The fact that results from both measurement methods are similar to each other, confirming the application of each in describing the output reliably (Table 3 ).

\section{METHOD III: Gravimetric method}

Since all of the samples were containing $0.327 \mathrm{~g}$ of calcium carbonate, $3.2700 \mathrm{mM}$ of $\mathrm{CO}_{2}$ is expected to be released from a stoichiometrical reaction. The amount of carbon dioxide release recorded from brand I and II were 2.727, and $2.999 \mathrm{mM}$ respectively which is 16.81 and $8.56 \%$ 
Table 4: Comparison of effervescence measured using different experimental methods

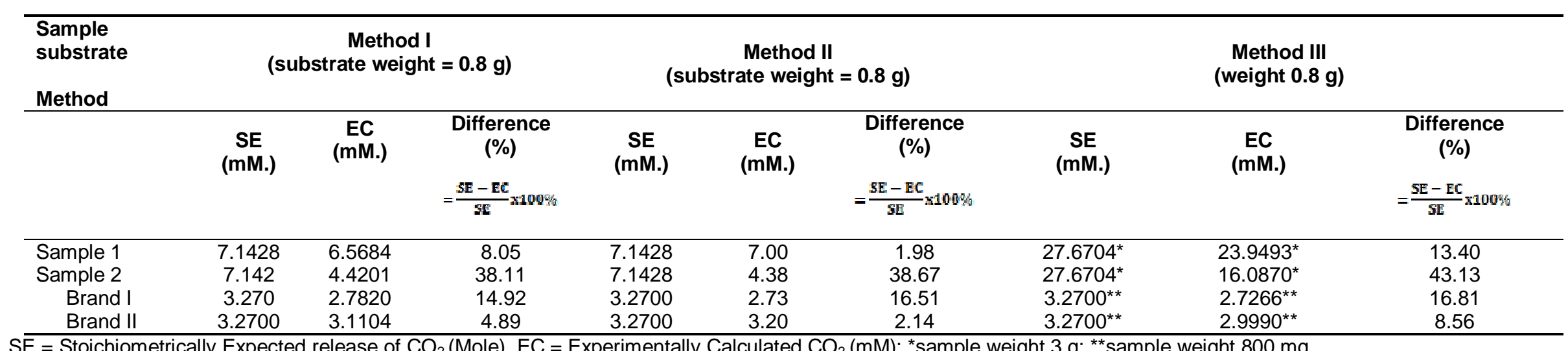




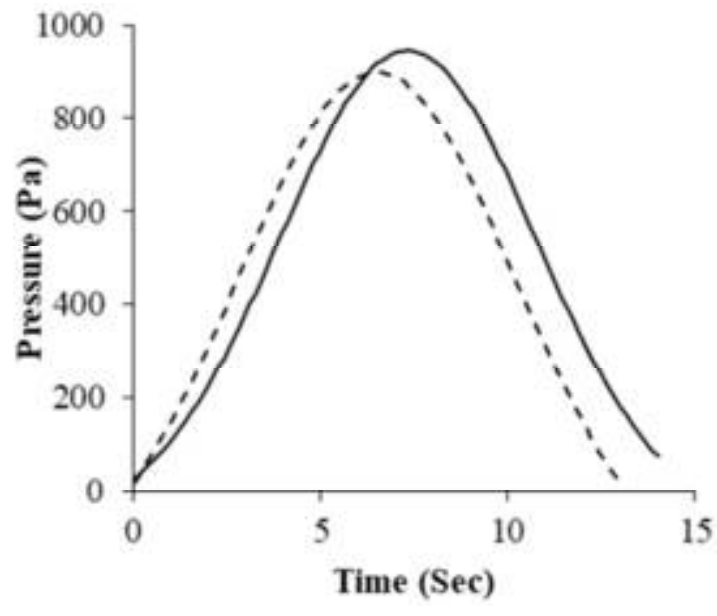

Figure 7: Effervescence-time profile of commercial effervescence powder brands containing $327 \mathrm{mg}$ of calcium carbonate as effervescent salt. solid line ( - ) describes pressure gradients from granules of brand I, dotted line (... ) describe pressure gradient from brand II granules.

lesser than that of stoichiometric approach (Table 3).

The fact that these results are comparable to Method I suggest application of this approach as an in-process quality control technique for the assessment of amount of effervescence lost/ left in an effervescent sample.

\section{DISCUSSION}

A proof of the concept study was performed to demonstrate the effect of formulation variables such as method of granulations on the product performance. In preliminary stage, modified Chittick apparatus was calibrated for the measurement of amount of $\mathrm{CO}_{2}$ produced using calcium carbonate. A reliable correlation of measured responses (amount of $\mathrm{CO}_{2}$ ) with theoretical estimate (stoichiometric predictions) confirmed the applicability of this instrument for formulation analysis (effervescent granules).

Formulations prepared by fusion and solvent assisted granulation were assessed for degree of effervescence using modified Chittick apparatus and gravimetric approach. Since the amount of carbon dioxide measured by modified Chitick and gravimetric method were same; it is presumed that variation between the formulation responses (amount of $\mathrm{CO}_{2}$ ) was linked to the method of preparation. It is evident from the results that $60 \%$ of effervescent activity can be conserved in a formulation by choosing appropriate (Fusion) method of granulation. A possible explanation in support of this selection is the fact that fusion method offers a limited availability of water (released on heating of hydrated salts) which serves as reaction medium for effervescence. It is envisaged that the modified Chittick apparatus can be used for the screening of other methods for effervescent formulations.

Formulations offered for sale in the market (labelled as brand I and brand II) were considered as positive control in terms of degree of effervescence. Likewise, the amount of carbon dioxide release was evaluated through modified Chittick apparatus as well as gravimetric method. The results suggest that the brands I and II contain degree of effervescence 85 and 95\% respectively, as compared with theoretical estimates. Possible explanation to this differences in effervescence may be due to the method of preparation, stages of product life cycle and efficiency of packaging materials used. Formulations prepared by fusion and solvents assisted granulation method offers different degree of effervescence 92 and $62 \%$, respectively. The former is comparable with the commercial brand II with degree of effervescence (95\%) confirming its significance for commercial manufacturing.

The applications for method of analysis can be extended to the evaluation of materials include presence of hydrates, particle size, in-process testing of powdered mixtures/granules porosity, massing behavior of the components in the product performance (degree of effervescence). This would extend the knowledge space for granulation phenomenon. A stability study aiming to measure the effervescence as a function of storage temperature and/or humidity would furbish realistic information for the calculation of shelf life. The methodology developed in this study could be used to measure in vitro performance of effervescent gastro retentive drug delivery system (GRDDS).

\section{CONCLUSION}

Measurement of effervescence by modified Chittick apparatus can find application in process analytical technology for the development of an optimized formulation. Screening of different methods for the preparation of effervescent granules is presented as a proof of this concept. Ease of measurement favors the utilization of this instrument at different stages of the manufacturing cycle.

\section{DECLARATIONS}

\section{Acknowledgement}

The authors wish to thank Bahauddin Zakariya University for funding this research project. 


\section{Conflict of Interest}

No conflict of interest associated with this work.

\section{Contribution of Authors}

The authors declare that this work was done by the authors named in this article and all liabilities pertaining to claims relating to the content of this article will be borne by them.

\section{REFERENCES}

1. Rahmanian $N$, Ghadiri $M$, Jia $X$, Stepanek $F$. Characterisation of granule structure and strength made in a high shear granulator. Powder Technol 2009; 192(2): 184-194.

2. Robinson JR, McGinity JW, inventors; Ethypharm, assignee. Effervescent granules and methods for their preparation. United States Patent US 6,071,539; 2000.

3. Johnson $T$, Gerson L, Hershcovici $T$, Stave $C$, Fass $R$. Systematic review: the effects of carbonated beverages on gastro-oesophageal reflux disease. Aliment Pharmacol Ther 2010; 31(6): 607-614.

4. Shalev $P$, inventor; Pollogen Ltd, assignee. Apparatus and method for using effervescent tablets for cosmetic care. United States patent application US 13/171,713. 2012.

5. Huang J, Fisher PR, Argo WR. A gasometric procedure to measure residual lime in container substrates. HortScience. 2007; 42(7): 1685-1689.

6. Loeppert RH, Suarez DL. "Carbonate and Gypsum" Publications from USDA-ARS / UNL Faculty 504, Chapter 15, 1996; pp 437-474.

7. Commission BP. British pharmacopoeia. British Pharmacopoeia Commission, London. 2009.

8. Ansel HC, Popovich NG, Allen LV. Pharmaceutical dosage forms and drug delivery systems. Baltimore: Williams \& Wilkins; 1995
9. Sharma N, Agarwal D, Gupta MK, Khinchi M. A comprehensive review on floating drug delivery system. Int J Res Pharm Biomed Sci 2011; 2(2): 428-441.

10. Amela J, Salazar R, Cemeli J. Methods for the determination of the carbon dioxide evolved from effervescent systems. Drug Dev Ind Pharm 1993; 19(9): 1019-1036.

11. Dreimanis A. Quantitative gasometric determination of calcite and dolomite by using Chittick apparatus. J Sedimentary Res 1962; 32(3): 520-529.

12. Machette M. Calcium and Magnesium. Field and laboratory procedures used in a soil chronosequence study. 1986;(1648): 30.

13. Forman $Y$, Levin $O$, Friedman $D$, Friedman $M$, inventors; Farmo-Nat Ltd, assignee. Effervescent granules. United States Patent US 5,948,439; 1999

14. Emery E, Oliver J, Pugsley T, Sharma J, Zhou J. Flowability of moist pharmaceutical powders. Powder Technol 2009; 189(3): 409-415.

15. Al-Hashemi HM, Al-Amoudi OS. A review on the angle of repose of granular materials. Powder Technol 2018; 330: 397-417.

16. Qu L, Zhou Q, Gengenbach T, Denman JA, Stewart PJ, Hapgood KP, Gamlen M, Morton DA. Investigation of the potential for direct compaction of a fine ibuprofen powder dry-coated with magnesium stearate. Drug Dev Industrial Pharm 2015 4; 41(5): 825-837.

17. Rosenboom JG, Antonyuk S, Heinrich S, Kraft $M$. Characterisation of lactose powder and granules for multivariate wet granulation modelling. Chem Eng Sci 2015; 123: 395-405.

18. Bhattacharyya S, Swetha G. Formulation and evaluation of effervescent granules of Fexofenadine hydrochloride. Pharm Innov 2014; 3(3, Part A): 1.

19. Shah RB, Tawakkul MA, Khan MA. Comparative Evaluation of Flow for Pharmaceutical Powders and Granules. AAPS PharmSciTech 2008; 9(1): 250-258. 